\title{
Enhanced synaptic long-term potentiation in the anterior cingulate cortex of adult wild mice as compared with that in laboratory mice Ming-Gao Zhao ${ }^{1,2}$, Hiroki Toyoda ${ }^{2}$, Yu-Kun Wang1 and Min Zhuo*2
}

\author{
Address: ${ }^{1}$ School of Pharmacy, Fourth Military Medical University, 17 Changle West Road, Xi'an 710032, Shaanxi, PR China and ${ }^{2}$ Department of \\ Physiology, Faculty of Medicine, University of Toronto, 1 King's College Circle, Toronto, M5S 1A8, Canada \\ Email: Ming-Gao Zhao - minggao.zhao@utoronto.ca; Hiroki Toyoda - hiroki.toyoda@utoronto.ca; Yu-Kun Wang - ykwang@fmmu.edu.cn; \\ Min Zhuo* - min.zhuo@utoronto.ca \\ * Corresponding author
}

Published: 16 May 2009

Molecular Brain 2009, 2:1। doi:10.1186/1756-6606-2-1I
Received: 15 April 2009

Accepted: 16 May 2009

This article is available from: http://www.molecularbrain.com/content/2/I/II

(C) 2009 Zhao et al; licensee BioMed Central Ltd.

This is an Open Access article distributed under the terms of the Creative Commons Attribution License (http://creativecommons.org/licenses/by/2.0), which permits unrestricted use, distribution, and reproduction in any medium, provided the original work is properly cited.

\begin{abstract}
Activation of N-methyl D-aspartate (NMDA) receptor is important for learning, memory and persistent pain. Genetic enhancement of NMDA receptor function by overexpressing NR2B subunit significantly enhances hippocampal long-term potentiation (LTP), behavioral learning as well as persistent pain. Recent studies found that NMDA NR2B subunits can undergo long-term upregulation in the brain under certain conditions including peripheral injury and environmental enrichment. Considering the fact that laboratory grown animals live in an artificial comfort environment, we wondered if NMDA receptor functions and its related LTP would differ in animals living in a natural wild environment. In this report we performed whole-cell patch-clamp recordings from both laboratory wild-type mice and wild mice from a natural environment. We found that LTP was significantly enhanced in the anterior cingulate cortex (ACC) of the wild mice as compared with that of laboratory mice. In parallel, NMDA receptor NR2B/total NMDA receptor mediated EPSC ratio was significantly increased in slices of wild mice. Our findings provide the first evidence that NMDA NR2B receptors play an important role in experience-dependent synaptic potentiation within the ACC in wild mice as previously reported in laboratory mice.
\end{abstract}

\section{Introduction}

The NMDA receptor plays a critical role in synaptic plasticity in many brain regions including the hippocampus, amygdala and anterior cingulate cortex (ACC) [1]. In most central synapses, NMDA receptors are composed of NR1, NR2 (A, B, C, and D), and NR3 (A and B) subunits. The formation of functional NMDA receptors requires a combination of NR1 and at least one NR2 subunit [2]. It is known that the NR2A and NR2B subunits predominate in the forebrain neurons, and the NR2A/NR2B subunit composition determines the functional properties of NMDA receptors $[3,4]$. Moreover, NMDA receptor subunits can undergo plastic changes in different regions of the brain during early development and different physiological/ pathological conditions [2,5-8]. For example, enriched animals display better leaning, enhanced hippocampal LTP, increased NMDA receptor NR2B subunit mediated currents in the forebrain $[9,10]$.

The importance of NMDA receptor NR2B subunit in hippocampal LTP and behavioral learning has been demonstrated by studies using transgenic mice with forebrain overexpression of NR2B subunits [11]. In these transgenic mice, hippocampal LTP is significantly enhanced, along with enhanced learning ability [11] and persistent pain [12]. In the ACC, NMDA receptor-dependent plasticity 
including LTP and long-term depression, depend on both NR2B and NR2A subunit-containing NMDA receptors $[13,14]$. NMDA NR2B receptors contribute to LTP induced by different induction protocols in the ACC [1416]. Our previous study provides strong evidence that NR2B-containing NMDA receptors in the ACC can contribute to the formation of classical contextual fear memory $[2,14]$.

It is well known that experience-dependent neuroanatomical and synaptic plasticity occurs in the brain. Previous studies reported that animals exposure to enriched environments results in increased cognitive and behavioral performances [17-19]. Furthermore, it has also been reported that environmental enrichment delayed the onset of neurodegenerative disorders [20,21], enhanced neurogenesis [22-24] and facilitated LTP [9]. The modification of synaptic plasticity and learning-related behaviors by the environment supports the notion that cognition is constantly influenced by natural selection and survival risks $[25,26]$. Most of the previous results have been reported in the hippocampus, a brain region thought to be important for spatial memory. However, less information is available for the ACC, a key structure of the forebrain region. The ACC plays an important role in sensory perception (including pain), learning, memory, emotion and executive functions [27]. Using animal models of inflammation or nerve injury, it has been reported that peripheral inflammation/nerve injury caused the long-term enhancement of presynaptic glutamate release and postsynaptic AMPA receptor mediated responses $[2,28-30]$. In addition, postsynaptic upregulation of NMDA receptor NR2B subunits in the ACC pyramidal neurons has also been reported after tissue inflammation [17]. Thus, it is conceivable that ACC synaptic functions may be modified by the natural environment. In this study, we took a different approach from previous studies of laboratory mice in enriched environment. We performed electrophysiological recordings from brain slices of wild mice obtained in a large city environment. We predict that these wild mice may have enhanced synaptic functions in the ACC, considering that they need to perform extra efforts daily to seek food and avoid dangerous predators.

\section{Results}

In our previous studies, we reported that laboratory mice exposed to an enriched environment (EE) showed enhanced long-term plasticity in the ACC [10]. Considering wild mice have developed in a sophisticated city environment, we expect that LTP may be enhanced in the ACC of the wild mice as compared with laboratory mice. We performed whole-cell patch-clamp recordings in visually identified pyramidal neurons in layer II/III of ACC slices. The pyramidal cells are further confirmed by the typical firing pattern induced by postsynaptic injection of depolarized currents. As previously reported [14], the pairing induction protocol produced a significant, long-lasting potentiation of synaptic responses in ACC slices of the control mice. In ACC slices of wild mice, we did not observe any obvious morphological differences. Furthermore, basic synaptic responses evoked by focal electrical stimulation are similar between slices of wild mice and that of control mice. We found, however, that the pairing protocol induced great LTP in slices of wild mice (see Figure 1). Interestingly, a comparison between control and wild mice revealed a significant increase in LTP in slices of wild mice (control group: $154.9 \pm 13.9 \%, \mathrm{n}=6$ slices from 4 mice; wild group: $192.6 \pm 10.9 \%, \mathrm{n}=9$ from 4 mice; $t$ test, $P<0.01$; Fig. $1 \mathrm{a}-\mathrm{c}$ ). This suggests that natural environment affects synaptic potentiation in the ACC.

One possible mechanism of enhanced LTP in the wild mice is increased total NMDA current in ACC synapses. To test this, AMPA receptor mediated EPSC/NMDA receptor mediated EPSC ratio was calculated from the peak amplitude of the CNQX-sensitive component measured at -70 $\mathrm{mV}$ and the peak amplitude of CNQX-resistant component measured at $+40 \mathrm{mV}$. Analysis of the currents obtained from the laboratory and wild mice showed that there was no difference in the AMPA/NMDA ratio (laboratory group: $1.85 \pm 0.26, \mathrm{n}=5$ slices from 4 mice; wild group: $1.57 \pm 0.27, \mathrm{n}=9$ from 4 mice; $t$-test, $P>0.05$; Fig. $2 \mathrm{a}$ and $2 \mathrm{~b})$.

Paired-pulse facilitation (PPF) is a simple form of synaptic plasticity, and is thought to be related to changes in presynaptic properties. To determine if PPF is affected in slices of wild mice, we performed recordings of PPF in slices from both groups. As shown in Figure 3, we found that PPF was similar between control and wild mice at all intervals tested (35-150 ms) (control group: $\mathrm{n}=9$ slices from 4 mice; wild group: $\mathrm{n}=9$ slices from 4 mice; $P$ > 0.05; Fig. $3 \mathrm{a}$ and $3 \mathrm{~b}$ ).

It is well known that NR2B-containing NMDA receptor contributes to synaptic LTP and behavioral learning $[11,17,31]$. A possible mechanism for an enhancement in ACC LTP is an alteration in NR2B/NR2A subunit composition in slices of wild mice. To test this possibility, we calculated the relative ratios of NR2A- and NR2B-mediated currents after applying selective NMDA NR2A antagonist NVP-AAM077 $(0.4 \mu \mathrm{M})$ and NR2B antagonist Ro 25$6981(0.3 \mu \mathrm{M})$ to estimate the contribution of NMDA NR2A vs NR2B to the total NMDA receptor mediated EPSC. We found that the ratio NR2B/NR2A mediated EPSCs (i.e., NR2B/NR2A) is significantly higher in wild mice than that in control mice (control group: $0.08 \pm$ $0.01, \mathrm{n}=5$ slices from 4 mice; wild group: $0.12 \pm 0.03, \mathrm{n}$ $=7$ from 4 mice; $t$-test, $P<0.05)$. We also estimated the 


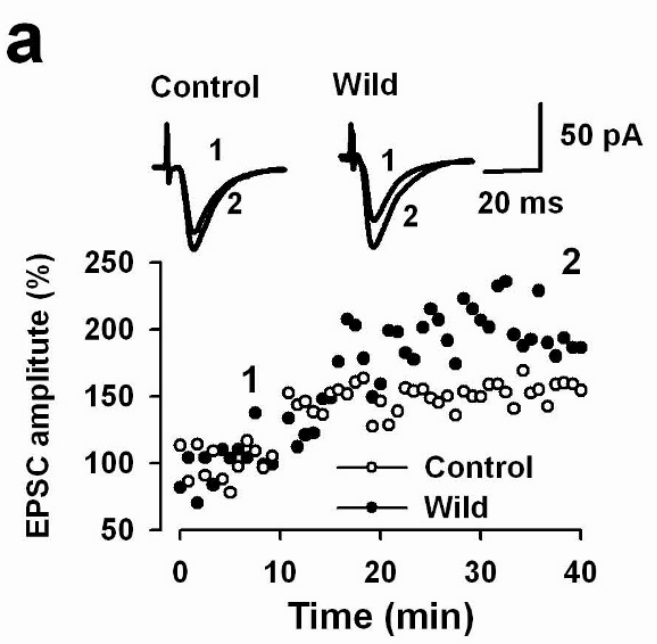

b
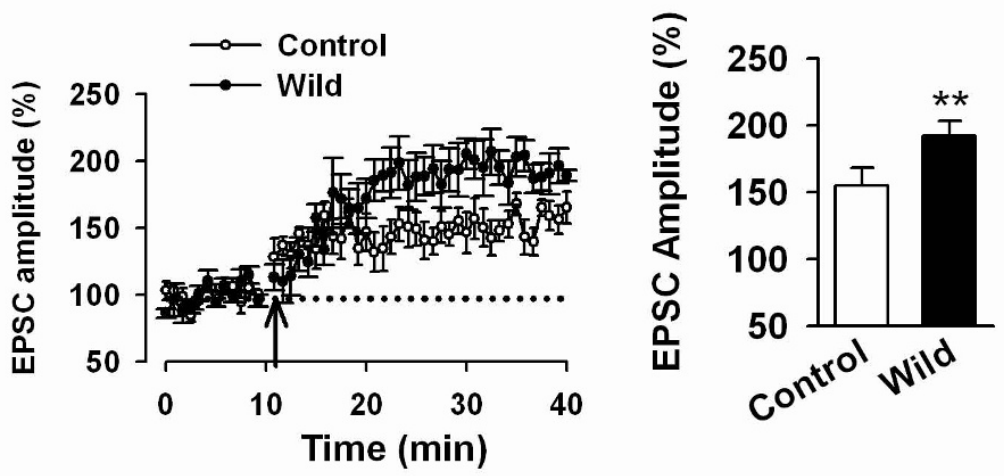

Figure I

Enhanced LTP induced by the pairing protocol in the ACC of wild mice. $a$ : Examples of synaptic potentiation of EPSCs in the layer II/III pyramidal cells of a wild mouse (filled circles) as compared with that in a laboratory (control) mouse (open circles); Inset: sample traces show averages of EPSCs 5 min before (I) and 30 min after (2) the paired training; $\boldsymbol{b}$ : Summarized data for LTP in slices of wild mice (filled circles) and control mice (open circles); c: Summarized data of EPSC amplitude 30 min after LTP induction in slices of control and wild mice. $* * P<0.01$, compared with laboratory group. Data are presented as mean \pm s.e.m.

NMDA NR2B subunit mediated currents over the total NMDA receptor mediated currents; and found that the $\mathrm{NR} 2 \mathrm{~B} /$ total NMDA EPSCs ratio was significantly greater in wild mice than laboratory mice (control group: $6.4 \pm$ $0.8 \%, \mathrm{n}=7$ slices from 3 mice; wild group: $9.3 \pm 1.6 \%, \mathrm{n}$ $=6$ from 3 mice; t-test, $\mathrm{P}<0.05$; Fig. $4 \mathrm{a}$ and $4 \mathrm{~b}$ ). These results suggest that there is more NR2B subunit composition in NMDA receptor-mediated synaptic transmission in the wild mice compared to the control mice within the ACC.

\section{Discussion}

In the present study, we have performed the first study of cingulate plasticity in wild mice. We hypothesize that a

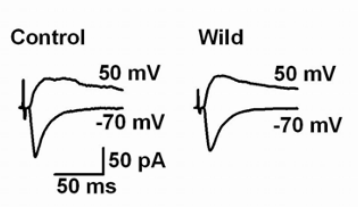

b

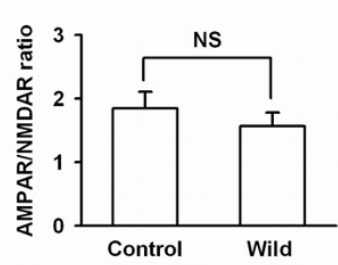

Figure 2

AMPA/NMDA ratio in the ACC of wild mice. $a$ :

Whole-cell recordings in pyramidal neurons from a laboratory and a wild mouse. AMPA and NMDA EPSCs were recorded at $-70 \mathrm{mV}$ and $+40 \mathrm{mV}$ respectively. b: Summary of the AMPA/NMDA ratio in neurons from laboratory and wild mice.
ACC neuronal synapses are likely modified to fit risky environment as compared with laboratory mice in a comfort animal facility. Our findings demonstrate that natural selection and survival risks facilitate LTP in the ACC. Considering the important contribution of NMDAR NR2B subunits to synaptic LTP and behavioral learning $[11,17,31]$, our results reinforce the role of NMDA NR2B subunit in central plasticity, and more importantly in a 'physiological' condition. Our results also raise the possi-

a

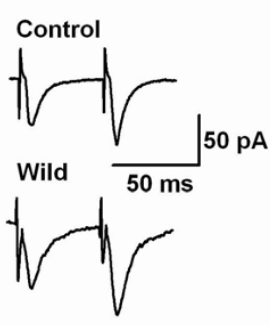

b

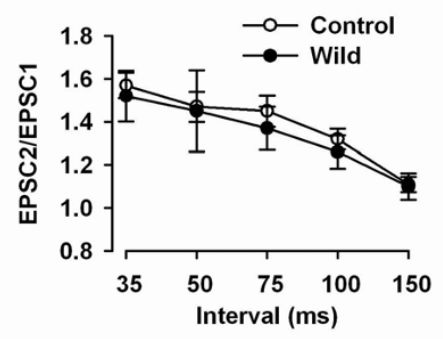

Figure 3

Paired-pulse facilitation (PPF) is similar in the ACC of wild and laboratory mice. $a$ : Examples of paired-pulse traces at an interval of $50 \mathrm{~ms}$ in wild and control mice. Recordings were performed from layer II/III pyramidal cells. b: Summarized PPF in different time intervals in control (open circles) and wild mice (filled circles). No significant different was detected between two groups. 


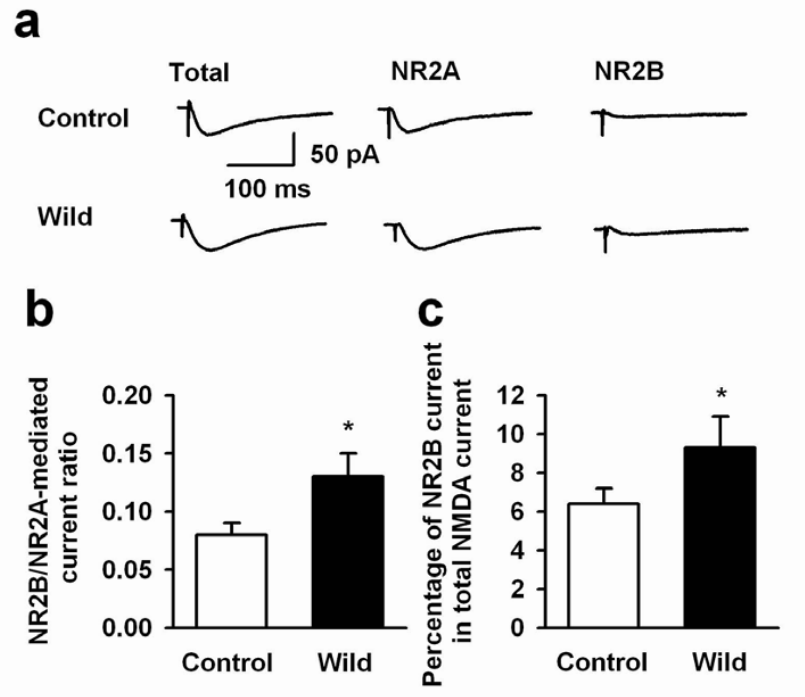

Figure 4

Enhanced NMDA receptor NR2B/NR2A ratio in the ACC of wild mice. $a$ : Representative traces showing NMDA receptor NR2A and NR2B subunit-mediated EPSCs from wild and control mice; $b$ : Summary of the NR2B/NR2A ratio in slices of control and wild mice. The NR2B/NR2A current ratio is enhanced in wild mice as compared with that in control mice; **P $<0.01$, compared with laboratory mice.

bility that experimental results from laboratory mice may not the same as those in wild mice. Despite the different in the contribution of NR2B subunit and cingulate LTP, we did find many common features between the neurons of wild mice and that of laboratory mice. Similar basal excitatory responses and PPF were found; suggesting that glutamate mediated excitatory transmission is identical.

The involvement of NMDA NR2B subunit in ACC-related physiological functions and pathological conditions has been reported recently (see $[2,27]$ for reviews). We have demonstrated that inflammation-related pain was selectively increased in mice with forebrain-targeted NR2B overexpression, while physiological or acute pain is not affected [12]. Such genetic manipulation of NMDA NR2B subunit overexpression can be at least mimicked in pathological conditions. For example, peripheral inflammation at one hindpaw in adult mice increased the expression level of NR2B proteins in the ACC [17]. Moreover, we have demonstrated that the exposure to enriched environment enhanced behavioral nociceptive responses to peripheral inflammation [10]. Consistently, we have shown that the NMDA NR2B receptors are involved in synaptic plasticity and contextual fear memory $[13,14]$. Together with the present findings, we argue that NMDA NR2B subunit is highly sensitive to an enriched environment and peripheral injury. Future studies are clearly needed to investigate the molecular mechanism for the upregulation of NMDA NR2B subunit in central neurons.

Considering the increases in NMDAR subunit NR2B/ NR2A current ratio in the wild mice, we expect that wild mice are likely superior in learning and memory as compared with control mice. Dissecting the molecular and cellular mechanisms in cingulate synaptic plasticity by using the wild mice may help us to understand the new insights of cortical plasticity and its related physiological functions.

\section{Methods \\ Animals}

We used adult wild mice captured by the Mouse/insect glue traps (plastic board). Usually, experiments were performed 4-8 hours after the mice were caught. The body weight of wild mice ranged from 22.5-31 gm. For comparison, eight-week-old C57BL/6 male mice with similar body weight were used as the laboratory control mice. These control mice were housed under a 12:12 light cycle with food and water provided ad libitum. The Animal Care and Use Committee of the Fourth Military Medical University (China) approved the animal protocol.

Brain slice electrophysiologyCoronal brain slices (300 $\mu \mathrm{m}$ ) from wild mice or laboratory mice, containing the ACC, were prepared using standard methods as previously described [12]. Slices were transferred to a submerged recovery chamber containing oxygenated $\left(95 \% \mathrm{O}_{2}\right.$ and $5 \% \mathrm{CO}_{2}$ ) artificial cerebrospinal fluid (ACSF) (in $\mathrm{mM}$ : $124 \mathrm{NaCl}, 2.5 \mathrm{KCl}, 2 \mathrm{CaCl}_{2}, 1 \mathrm{MgSO}_{4}, 25 \mathrm{NaHCO}_{3}, 1$ $\mathrm{NaH}_{2} \mathrm{PO}_{4}, 10$ glucose) at room temperature for at least 1 h.

Experiments were performed in a recording chamber on the stage of an Axioskop 2FS microscope with infrared DIC optics for visualizing whole-cell patch clamp recordings. Excitatory postsynaptic currents (EPSCs) were recorded from layer II-III neurons using an Axon 200B amplifier (Axon Instruments, CA) and stimulations were delivered using a bipolar tungsten stimulating electrode placed in layer V of the ACC. The $\alpha$-amino-3-hydroxy-5methyl-4-isoxazolepropionic acid (AMPA) receptor-mediated EPSCs were induced by repetitive stimulations at $0.02 \mathrm{~Hz}$ and neurons were voltage clamped at $-70 \mathrm{mV}$. The recording pipettes (3-5 M 2 ) were filled with solution containing (mM) 145 K-gluconate, $5 \mathrm{NaCl}, 1 \mathrm{MgCl}_{2}, 0.2$ EGTA, 10 HEPES, $2 \mathrm{Mg}$-ATP, and $0.1 \mathrm{Na}_{3}$-GTP (adjusted to $\mathrm{pH} 7.2$ with $\mathrm{KOH}$ ).

LTP was induced within $12 \mathrm{~min}$ after obtaining stable EPSCs to prevent the washout effect. The protocol involved paired presynaptic 80 pulses at $2 \mathrm{~Hz}$ with postsynaptic depolarization at $+30 \mathrm{mV}$ (referred to as pairing 
training). The NMDA receptor-mediated component of EPSCs was pharmacologically isolated in ACSF containing: CNQX $(20 \mu \mathrm{M})$ and picrotoxin $(100 \mu \mathrm{M})$. The patch electrodes contained (in $\mathrm{mM}$ ) 102 cesium gluconate, 5 TEA-chloride, $3.7 \mathrm{NaCl}$, 0.2 EGTA, 20 HEPES, 2 MgATP, $0.3 \mathrm{NaGTP}$, and 5 QX-314 chloride (adjusted to pH 7.2 with $\mathrm{CsOH}$ ). Neurons were voltage clamped at $-30 \mathrm{mV}$ and NMDA receptor-mediated EPSCs were evoked at 0.05 Hz. NVP-AAM077 $(0.4 \mu \mathrm{M})$ and Ro25-6981 $(0.3 \mu \mathrm{M})$ were bath applied sequentially to assess the NR2A- and NR2B-components of EPSCs. For AMPA EPSC/NMDA EPSC ratio experiments, AMPA receptor mediated EPSCs were recorded at a holding potential of $-70 \mathrm{mV}$ and picrotoxin $(100 \mu \mathrm{M})$ was added to ACSF to inhibit IPSCs. After recording AMPA receptor-mediated currents, NBQX (10 $\mu \mathrm{M})$ was added to ACSF and holding potential was changed to $+40 \mathrm{mV}$ to record NMDA receptor mediated EPSCs. The AMPA/NMDA ratio was calculated by the peak amplitude of mean traces. The access resistance was 15-30 $\mathrm{M} \Omega$ and was monitored throughout the experiment. Data were discarded if access resistance changed by more than $15 \%$ during an experiment.

\section{Data analyses}

Results were analyzed by t-test, paired t-test, or two-way ANOVA followed by post-hoc Student-Newman-Keuls test to identify significant differences. All data are expressed as mean \pm S.E.M. In all cases, $P<0.05$ was considered statistically significant.

\section{Abbreviations}

ACC: anterior cingulate cortex; ACSF: artificial cerebrospinal fluid; AMPA: $\alpha$-amino-3-hydroxy-5-methyl-4-isoxazolepropionic acid; EE: enriched environmental; EPSC: excitatory postsynaptic current; LTP: long-term potentiation; NMDA: N-methyl D-aspartate receptor; PPF: pairedpulse facilitation.

\section{Competing interests}

The authors declare that they have no competing interests.

\section{Authors' contributions}

MGZ is responsible for performance of electrophysiology and writing the manuscript. HT is responsible for performance of electrophysiology. YKW is responsible for some experiments as well as data analyses. MZ is responsible for experimental design and writing the manuscript. All authors read and approved the final manuscript.

\section{Acknowledgements}

This work was supported by grants from the EJLB-CIHR Michael Smith Chair in Neurosciences and Mental Health, ClHR operating grants CIHR8I 086 and CIHR84256, Canada Research Chair, and NeuroCanada to M.Z. and National Natural Science Foundation of China (30770686) to MG.Z.

\section{References}

I. Bliss TV, Collingridge GL: A synaptic model of memory: longterm potentiation in the hippocampus. Nature 1993, 36 I:31-39.

2. Zhuo M: Plasticity of NMDA receptor NR2B subunit in memory and chronic pain. Mol Brain 2009, 2:4.

3. Loftis JM, Janowsky A: The $\mathbf{N}$-methyl-D-aspartate receptor subunit NR2B: localization, functional properties, regulation, and clinical implications. Pharmacol Ther 2003, 97:55-85.

4. Monyer H, Burnashev N, Laurie DJ, Sakmann B, Seeburg PH: Developmental and regional expression in the rat brain and functional properties of four NMDA receptors. Neuron 1994, 1 2:529-540.

5. Arrigoni E, Greene RW: Schaffer collateral and perforant path inputs activate different subtypes of NMDA receptors on the same CAI pyramidal cell. Br J Pharmacol 2004, I 42:3 I 7-322.

6. Ritter LM, Vazquez DM, Meador-Woodruff JH: Ontogeny of ionotropic glutamate receptor subunit expression in the rat hippocampus. Brain Res Dev Brain Res 2002, I39:227-236.

7. Sheng M, Cummings J, Roldan LA, Jan YN, Jan LY: Changing subunit composition of heteromeric NMDA receptors during development of rat cortex. Nature 1994, 368: |44-I47.

8. Munoz A, Woods TM, Jones EG: Laminar and cellular distribution of AMPA, kainate, and NMDA receptor subunits in monkey sensory-motor cortex. J Comp Neurol 1999, 407:472-490.

9. Duffy SN, Craddock KJ, Abel T, Nguyen PV: Environmental enrichment modifies the PKA-dependence of hippocampal LTP and improves hippocampus-dependent memory. Learn Mem 2001, 8:26-34.

10. Shum FW, Wu LJ, Zhao MG, Toyoda H, Xu H, Ren M, Pinaud R, Ko SW, Lee YS, Kaang BK, Zhuo M: Alteration of cingulate longterm plasticity and behavioral sensitization to inflammation by environmental enrichment. Learn Mem 2007, I 4:304-3 I 2.

II. Tang YP, Shimizu E, Dube GR, Rampon C, Kerchner GA, Zhuo M, Liu $G$, Tsien JZ: Genetic enhancement of learning and memory in mice. Nature 1999, 401:63-69.

12. Wei F, Wang GD, Kerchner GA, Kim SJ, Xu HM, Chen ZF, Zhuo M: Genetic enhancement of inflammatory pain by forebrain NR2B overexpression. Nat Neurosci 200I, 4: I64-I69.

13. Toyoda $H$, Zhao MG, Zhuo M: Roles of NMDA receptor NR2A and NR2B subtypes for long-term depression in the anterior cingulate cortex. Eur J Neurosci 2005, 22:485-494.

14. Zhao MG, Toyoda H, Lee YS, Wu LJ, Ko SW, Zhang XH, Jia Y, Shum $\mathrm{F}, \mathrm{Xu} \mathrm{H}$, Li BM, et al:: Roles of NMDA NR2B subtype receptor in prefrontal long-term potentiation and contextual fear memory. Neuron 2005, 47:859-872.

I5. Liu L, Wong TP, Pozza MF, Lingenhoehl K, Wang Y, Sheng M, Auberson YP, Wang YT: Role of NMDA receptor subtypes in governing the direction of hippocampal synaptic plasticity. Science 2004, 304: $1021-1024$.

16. Zhang XH, Wu LJ, Gong B, Ren M, Li BM, Zhuo M: Induction- and conditioning-protocol dependent involvement of NR2B-containing NMDA receptors in synaptic potentiation and contextual fear memory in the hippocampal CAI region of rats. Mol Brain 2008, I:9.

17. Wu LJ, Toyoda H, Zhao MG, Lee YS, Tang J, Ko SW, Jia YH, Shum $\mathrm{FW}$, Zerbinatti $\mathrm{CV}, \mathrm{Bu} \mathrm{G}$, et al: Upregulation of forebrain NMDA NR2B receptors contributes to behavioral sensitization after inflammation. J Neurosci 2005, 25: I I I07-I I I I6.

18. Rutten A, van Albada M, Silveira DC, Cha BH, Liu X, Hu YN, Cilio MR, Holmes GL: Memory impairment following status epilepticus in immature rats: time-course and environmental effects. Eur J Neurosci 2002, 16:501-5I3.

19. Allman JM, Hakeem A, Erwin JM, Nimchinsky E, Hof P: The anterior cingulate cortex. The evolution of an interface between emotion and cognition. Ann N Y Acad Sci 200I, 935:107-I I7.

20. Spires TL, Grote HE, Varshney NK, Cordery PM, van Dellen A, Blakemore $C$, Hannan AJ: Environmental enrichment rescues protein deficits in a mouse model of Huntington's disease, indicating a possible disease mechanism. J Neurosci 2004, 24:2270-2276.

21. Arendash GW, Garcia MF, Costa DA, Cracchiolo JR, Wefes IM, Potter $\mathrm{H}$ : Environmental enrichment improves cognition in aged Alzheimer's transgenic mice despite stable beta-amyloid deposition. Neuroreport 2004, I5:|75|-1754. 
22. Catlow BJ, Rowe AR, Clearwater CR, Mamcarz M, Arendash GW, Sanchez-Ramos J: Effects of environmental enrichment and physical activity on neurogenesis in transgenic PSI/APP mice. Brain Res 2009, I 256: I73-179.

23. Kempermann G, Kuhn HG, Gage FH: More hippocampal neurons in adult mice living in an enriched environment. Nature 1997, 386:493-495.

24. Gaulke LJ, Horner PJ, Fink AJ, McNamara CL, Hicks RR: Environmental enrichment increases progenitor cell survival in the dentate gyrus following lateral fluid percussion injury. Brain Res Mol Brain Res 2005, 141:138-150.

25. Hicks RR, Zhang L, Atkinson A, Stevenon M, Veneracion M, Seroogy $K B$ : Environmental enrichment attenuates cognitive deficits, but does not alter neurotrophin gene expression in the hippocampus following lateral fluid percussion brain injury. Neuroscience 2002, I I 2:63|-637.

26. Pham TM, Soderstrom S, Winblad B, Mohammed AH: Effects of environmental enrichment on cognitive function and hippocampal NGF in the non-handled rats. Behav Brain Res 1999, 103:63-70.

27. Zhuo M: Cortical excitation and chronic pain. Trends Neurosci 2008, 31 : 199-207.

28. Toyoda $\mathrm{H}$, Zhao MG, Zhuo M: Enhanced quantal release of excitatory transmitter in anterior cingulate cortex of adult mice with chronic pain. Mol Pain 2009, 5:4.

29. Xu H, Wu LJ, Wang H, Zhang X, Vadakkan KI, Kim SS, Steenland HW, Zhuo M: Presynaptic and postsynaptic amplifications of neuropathic pain in the anterior cingulate cortex. J Neurosci 2008, 28:7445-7453.

30. Zhao MG, Ko SW, Wu LJ, Toyoda H, Xu H, Quan J, Li J, Jia Y, Ren M, $\mathrm{Xu} Z \mathrm{ZC}$, Zhuo M: Enhanced presynaptic neurotransmitter release in the anterior cingulate cortex of mice with chronic pain. J Neurosci 2006, 26:8923-8930.

31. Wong RW, Setou M, Teng J, Takei Y, Hirokawa N: Overexpression of motor protein KIF I7 enhances spatial and working memory in transgenic mice. Proc Natl Acad Sci USA 2002, 99:14500-14505.

Publish with Bio Med Central and every scientist can read your work free of charge

"BioMed Central will be the most significant development for disseminating the results of biomedical research in our lifetime. "

Sir Paul Nurse, Cancer Research UK

Your research papers will be:

- available free of charge to the entire biomedical community

- peer reviewed and published immediately upon acceptance

- cited in PubMed and archived on PubMed Central

- yours - you keep the copyright
BioMedcentral 